\title{
STRATEGIC MULTIPLE SENSOR DATA FUSION FOR TIME-CRITICAL NATURAL DISASTER RESPONSE
}

\author{
S. Kim ${ }^{\text {a, }}$, S. Goo ${ }^{\text {a }, Y . ~ P a r k ~}{ }^{\text {a }}$, J. Choi $^{\text {a }}$, M. Cho ${ }^{\text {a }}$ \\ ${ }^{a}$ NDMI, MOPAS, 136 Mapo-daero, Mapo-gu, Seoul, Korea - (sskim73, gsh7934, clubpark, jwchoi74, \\ geoisrs)@korea.kr
}

Commission IV, WG IV/8

KEY WORDS: Multi-sensor, Data Fusion, Natural Disaster, Timely Response

\begin{abstract}
:
Recently, large-scale natural disasters have been occurred in the various areas of the world. The super-sized multi-hazards over the world have required more and more scientific and systematic measurement technologies in the fields of management and response of natural disaster. The purpose of this study is to suggest a multi-sources data fusion approach like LiDAR, aerial images, and satellite imagery and evaluate its applicability for timely natural disaster response. In order to achieve a high-accurate mapping in time in disaster situation, we proposed strategic approach using multi-sensors data fusion in this paper. The data fusion approach using the satellite imagery, low altitude aerial imagery from the mini-UAV and the small manned helicopter, and LiDAR point data simultaneously is expected to enhance the capability for more accurate damage analysis and the faster hazard mapping.
\end{abstract}

\section{INTRODUCTION}

Recently natural disaster has occurred in a different and unexpected aspect unlike the past. To respond a variety of natural disasters around the world in time and decrease its damage, effective countermeasure has been prepared quickly at the national level.

Especially, the latest submarine earthquake with 9.0 magnitude and consecutive tsunami in Japan brought unprecedented damages such as enormous casualties and tremendous economic loss. These situations of recent disaster require a strategic approach with the multi-sensors data integration to respond the natural disaster effectively. In order to achieve a high-accurate mapping on time in disaster situation, we proposed strategic approach using data fusion acquired from multi-sensors. As the experimental data, different types of data were utilized such as pre- and post- disaster aerial photos, the aerial and the terrestrial LiDAR data, the Optic and SAR images, various maps in NDMS's (National Disaster Management System) database in this study. For extracting damage extent caused by landslide and flood for study area, pre- and post-disaster imagery were used to apply for image algebra change detection algorithm. Through GIS-based analysis, added valuable disaster information were extracted and hazard maps related to landslide were generated (Figure 1).

The purpose of this study is to suggest a data fusion approach from different types of sensor and evaluate the applicability for timely natural disaster response. The data fusion using the satellite imagery, low altitude aerial imagery from the miniUAV and the small manned helicopter, and LiDAR point data simultaneously is expected to enhance the capability for more accurate damage analysis and the faster hazard mapping.

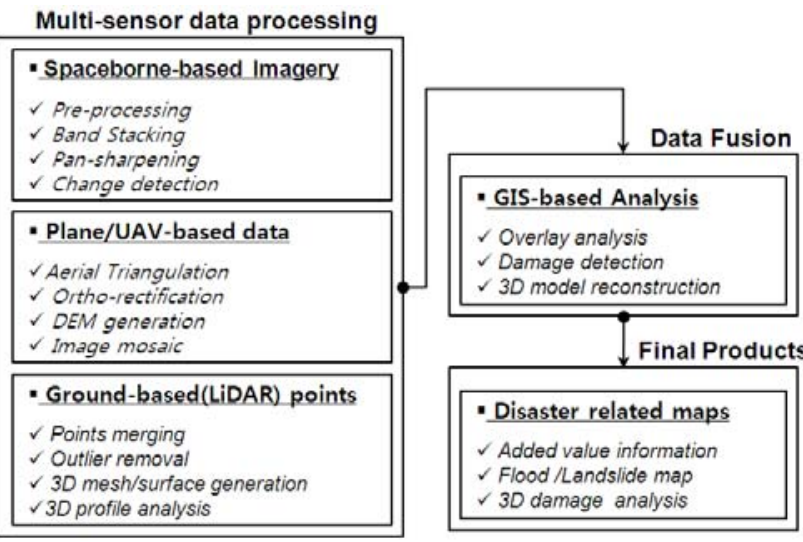

Figure 1. Flowchart of multi-sensor data processing

\section{EMERGENCY MAPPING TEAM}

\subsection{Establishment of Emergency Mapping Team and Activities for Disaster Response}

Seoul city, the capital of South Korea, has experienced heavy rainfall about $600 \mathrm{~mm}$ from July 26-28, 2011. It induced unexpected landslides and flood disasters on the southern part of Seoul city. Landslides around Mt. Umyeon killed 18 people and destroyed some motorways adjoined to the Han River by flooding (NDMS, 2011). Economic damages were estimated to be in the hundreds of millions US dollars.

\subsection{EMT Configuration}

In order to rapid respond for landslide and flood damage by heavy rainfall, National Disaster Management Institute (NDMI) organized Emergency Mapping Team (EMT) composed of

\footnotetext{
* Corresponding author.
} 
more than 10 university-industry-institute cooperative organizations as below.

- Disaster-related Organizations (3) : International Charter-Space and Major Disasters, Korean Aerospace Research Institute (KARI), National Disaster Management Institute (NDMI)

- Educational Sectors (3) : University of Seoul, Yonsei University, Chungnam National University

- Industrial Sectors (5) : Korea Cadastral Survey Co., Hansung T\&I Co., Satrec Initiative Co., MD Korea Co., Geosystems Co.

This group actually joint following activities voluntarily; timely acquire and process field investigation data of disaster area, analyze collected data, and generate hazard maps for emergency disaster response.

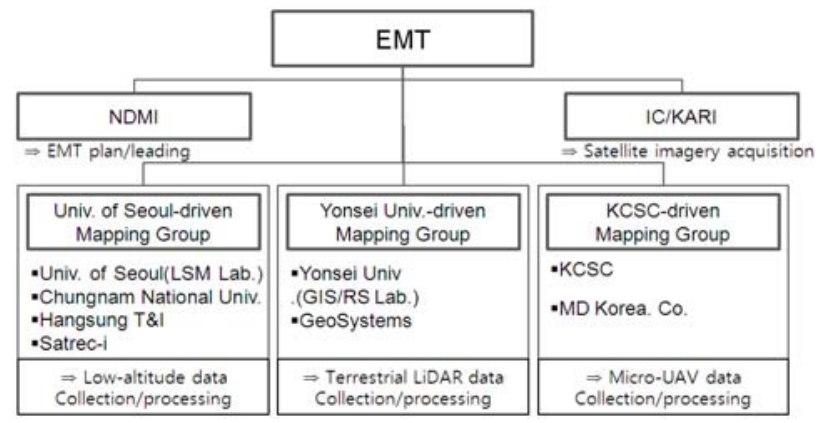

Figure 2. Configuration of EMT

\section{MULTI-SENSOR DATA ACQUISITION SYSTEM}

In this study, Space-, Air- and ground-based platforms were introduced for effective multi-sensor data acquisition and rapid mapping of disaster area.

\subsection{Small Manned Helicopter-based RAMS}

At various emergency situations such as natural disasters or accidents, the activation of effective disaster management system is indispensable for rapid responses. As the part of an applied research for rapid mapping, LSM laboratory of University of Seoul has developed RAMS (Real-time Aerial Monitoring System) which can monitor the emergency situations from the air using different kinds of sensors: digital camera, laser scanner, GPS, IMU etc. Each specification of sensors mounted on RAMS respectively is same as Table 1.

Table 1. Sensor specification on board RAMS

\begin{tabular}{|l|c|l|}
\hline $\begin{array}{c}\text { Characte } \\
\text { ristics }\end{array}$ & $\begin{array}{c}\text { Model } \\
\text { (Manufacturer) }\end{array}$ & \multicolumn{1}{c|}{ Description } \\
\hline $\begin{array}{l}\text { Digital } \\
\text { Camera }\end{array}$ & $\begin{array}{c}\text { XMV-16M } \\
\text { (Illunis) }\end{array}$ & $\begin{array}{l}\text { Weight: 0.47 kg } \\
\text { Frame rate: } 3 \mathrm{~Hz} \\
\text { effective pixels: } 4872 \times 3248,7.4 \mu \mathrm{m}\end{array}$ \\
\hline $\begin{array}{l}\text { Laser } \\
\text { Scanner }\end{array}$ & $\begin{array}{c}\text { LMS-Q240i } \\
\text { (Riegl) }\end{array}$ & $\begin{array}{l}\text { Weight: } 7 \mathrm{~kg} \\
\text { FOV: } 80^{\circ}\left( \pm 40^{\circ}\right) \\
\text { Scanning rate: } 6 \sim 80 \mathrm{~Hz}\end{array}$ \\
\hline GPS & $\begin{array}{c}\text { OEMV-3 } \\
\text { (Novatel) }\end{array}$ & $\begin{array}{l}\text { Position accuracy: } 1.8 \mathrm{~m} \\
\text { weight: } 0.075 \mathrm{~kg} \\
\text { data rate: } 20 \mathrm{~Hz}\end{array}$ \\
\hline IMU & $\begin{array}{l}\text { HG1700 } \\
\text { (Honeywell) }\end{array}$ & $\begin{array}{l}\text { velocity accuracy: } 0.02 \mathrm{~m} / \mathrm{s} \\
\text { weight: } 3.4 \mathrm{~kg} \\
\text { data rate: } 100 \mathrm{~Hz}\end{array}$ \\
\hline
\end{tabular}

It consists of both aerial and ground segments. The aerial segment acquires the sensory data about the damaged areas and transmits them to the ground segment in real-time. The ground segment receives the sensory data and rapidly processes them to generate geo-spatial information (Lee et al., 2011a).

\subsection{Quadcopter Micro UAV : MD(MicroDrones)4-1000}

Many studies have been performed for a wide range of applications of UAV (Unmanned Aerial Vehicle) reached from the civil and commercial market to the military field (Haarbrink et al., 2006; Bendea et al., 2008; Everaerts, E. 2008; Grenzdörffe et al., 2008). UAVs have outstanding merits for low altitude photogrammetric mapping : 1) to perform very low altitude aerial photography at cloudy day, 2) to get full image of city building form different direction by complicated flying, 3) to supply a cheap and easy system for engineering organization for high frequency needs of aerial photogrammetric survey (Lin, 2008). With those specifications of UAVs, we attempted to apply to the field of natural disaster management.

MD4-1000 is a AUMAV (Autonomous Unmanned Micro Aerial Vehicle) designed to perform many aerial tasks: surveying, exploration, surveillance, and communication etc. A modular payload concept allows the UAV MD4-1000 as well to carry a most diverse range of imaging, video and other sensor systems. The Microdrone UAV is consisted of OGPSMAG GPS (Global Positioning System), still camera (Olympus E-p1) with resolution of $12 \mathrm{M}(4000 \times 3000$ pixels $)$, ground station set, Lipo battery and charger, carbon blade, etc (Lee et al., 2011b). The characteristics of MD4-1000 are as following Table 2.

Table 2. Characteristics of MD4-1000

\begin{tabular}{|l|l|}
\hline \multicolumn{1}{|c|}{ Characteristics } & \multicolumn{1}{c|}{ Description } \\
\hline Flight Speed & $15.0 \mathrm{~m} / \mathrm{s}$ \\
\hline Empty Weight & $2,560 \mathrm{~g}$ \\
\hline Recommended payload & $800 \mathrm{~g}$ \\
\hline dimensions & $\begin{array}{l}1,030 \mathrm{~mm} \\
\text { (Length between rotor shaft ) }\end{array}$ \\
\hline Flight time & Up to 70 minutes \\
\hline Maximum take-off weight & $5,550 \mathrm{~g}$ \\
\hline
\end{tabular}

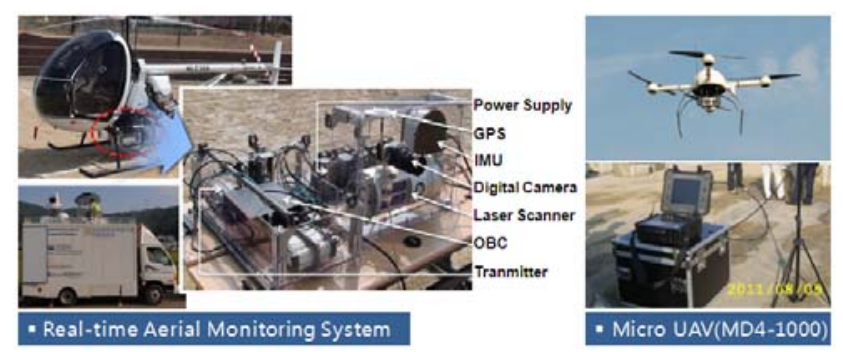

Figure 3. RAMS(left) and MD4-1000(right)

\subsection{LiDAR scanner}

For rapid detection and follow-up measures of natural disaster, a fast and accurate hazard monitoring system using both terrestrial and airborne LiDAR was suggested in this study.

To conduct volume analysis for the damaged area, 3D point clouds data were acquired from three types of terrestrial LiDAR scanners. After pre-processing such as registration of point cloud data, noise filtering, and geo-referencing, we compared the terrestrial LiDAR data with the airborne LiDAR data, which 
was obtained prior to the disaster, then quantified changed volume for the damaged area (Sohn et al., 2011).

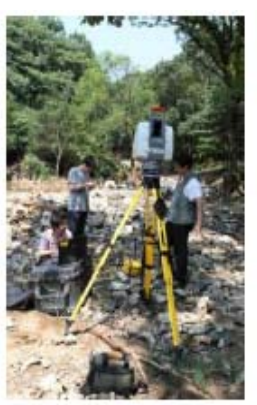

Leica

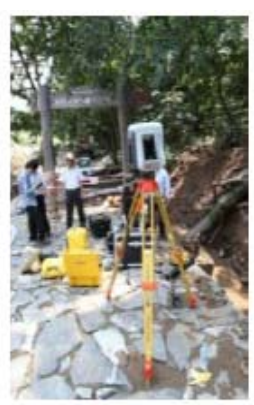

Trimble GX

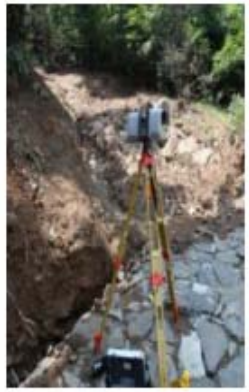

Trimble CX
Figure 4. Terrestrial LiDAR scanner

\section{EXPERIMENTAL RESULT}

\subsection{Study Area}

Mt. Umyeon is located on a central region of Seoul and surrounded by urban facilities. Analysis results from a forest map produced by Korea Forest Service showed that most forest types around Mt. Umyeon were the deciduous and the mixed stand forest and over 30 years old tree reached $97 \%$ nearly. A natural ecological park with a small-size reservoir was developed at the southern area of Mt. Umyeon. Around Mt. Umyeon, there was no district zone designated as a disaster risk.

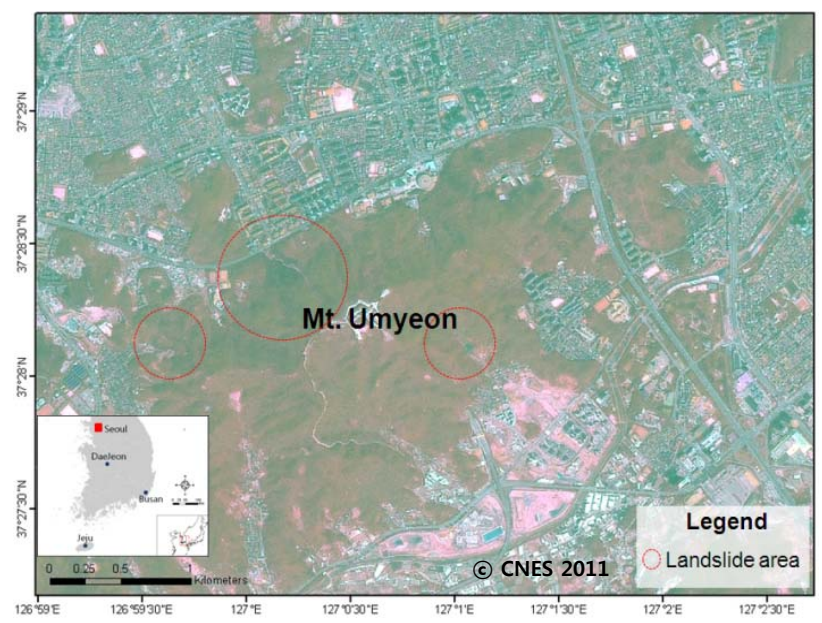

Figure 5. Location of Study Area (Mt. Umyeon)

\subsection{Multi-sensor Data Processing for Damage Analysis}

In order to extract the damaged extent, pre- and post- aerial photos, a variety of digital map from NDMS (National Disaster Management System) Database, and the Optic and SAR images from International Charter were utilized in this study. Simultaneously, point clouds of the landslide area were collected and processed through the terrestrial and the aerial LIDAR. For damage extent extraction caused by landslide and flood for the study area, collected pre- and post-disaster imagery were used as an experimental data to apply for image algebra change detection algorithm (John, 1996).

$$
D_{1 ! k}=3 V_{i j s}(1)-3 V_{i j k}(2)+c
$$

Where,

$\mathbb{D}_{i j k}=$ change pixel value

$\left.\mathrm{B}^{\mathrm{r}}[1] \mathrm{j}, \mathrm{L}\right)=$ brightness pixel value at time 1

$\mathrm{z}_{\mathrm{i} i \mathrm{k}}(2)=$ brightness pixel value at time 2

$\mathbf{c}=$ constant

The total landslide extent of three damaged regions (red collar polygons on Figure 6) in the study area estimated by change detection algorithm was about 8.6 ha.

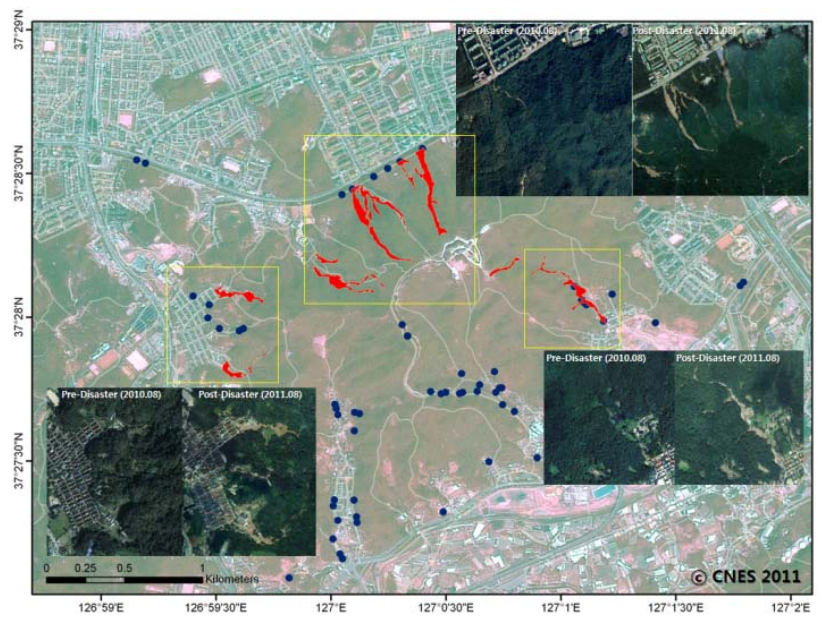

Figure 6. Extraction of damage area by landslide

Aerial photos from the small manned helicopter and Unmanned Aerial Vehicle were conducted by post-processing procedure. For geometric correction and rectification of aerial images through an aerial triangulation (AT), Ground Control Points (GCPs) were extracted from 1/1,000 scale digital map produced at National Geographic Information Institute (NGII). After Aerial triangulation processing, the digital terrain model with $1 \mathrm{~m}$ spatial resolution and $5 \mathrm{~cm}$-level ortho-rectified photos were generated. Final mosaicked ortho-imagery was made using DTM data and ten ortho-rectified photos with an accuracy of $1.45 \mathrm{~m}$ (RMSE).
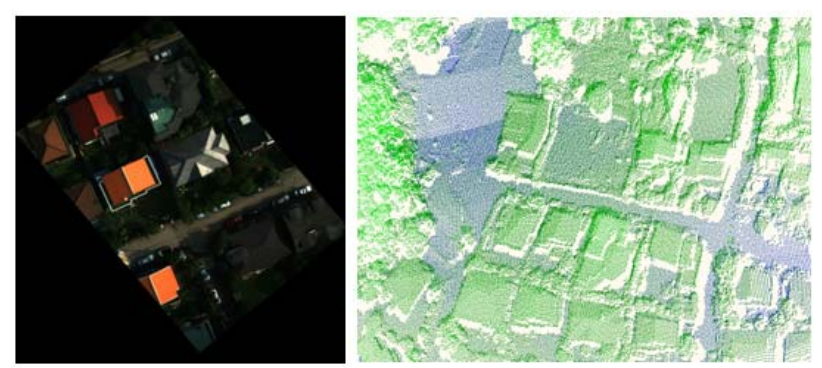

Figure 7. Ortho-rectified photos (left) and aerial LiDAR by RAMS (right)

Before terrestrial LiDAR scanning, Ground Control Points (GCPs) survey was carried out using static GPS method as setting up eight control points around the landslide and the reservoir's bank collapse area for almost eight hours. The data process of collected LiDAR point clouds was performed as following; point cloud geo-referencing and registration, outlier eliminating, 3D mesh/surface generating and editing, DTM generating, and 3D modelling of the study area. 

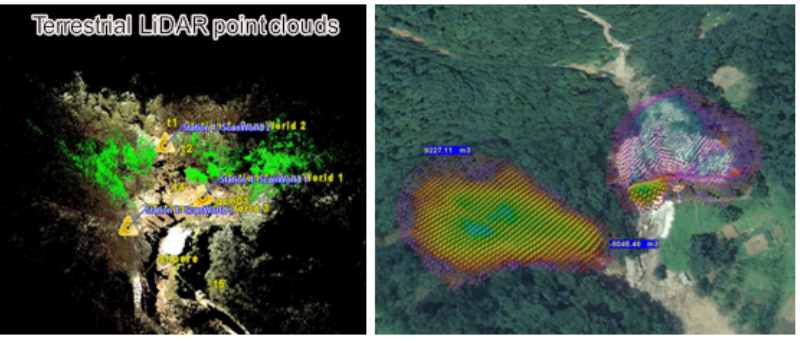

Figure 8. LiDAR point clouds (left) and volume analysis in study area (right)

Data fusion using LiDAR point clouds and ortho-imagery of damage area allows us to get more detailed three-dimensional damage information such as a damage extent analysis, a profile analysis using data fusion between pre- and post-disaster LiDAR data and aerial photos, and a run-off debris volume analysis of landslides region (Table 3 ).

Table 3. Damage analysis results

\begin{tabular}{|c|c|c|}
\hline & Damaged area $\left(\mathrm{m}^{2}\right)$ & Damaged volume $\left(\mathrm{m}^{3}\right)$ \\
\hline Fill & 1,499 & 4,096 \\
\hline Cut & 6,380 & 52,477 \\
\hline
\end{tabular}

\section{CONCLUSION}

To respond a variety of natural disasters in time occurred around the world and decrease its damage, effective countermeasure has been prepared quickly at the national level. This paper suggests a multi-sensor data fusion approach for timely disaster and evaluates the accurate and quantitative analysis results for rainfall induced landslides damages in Korea.

Analysis results revealed that the accuracy of an ortho-image for study was $1.45 \mathrm{~m}$ and the damage extents caused by landslide using change detection algorithm was estimated about 8.6 ha. The damaged area and the 3D volume of run-off debris calculated with LiDAR data acquired during pre and post disaster period was $6,380 \mathrm{~m}^{2}$ and $52,477 \mathrm{~m}^{3}$ respectively.

The multi-source data fusion approach using ortho-image, point clouds as well as field investigation data is expected to enhance the capability for more accurate damage analysis and the faster hazard mapping.

\section{REFERENCES}

Bendea , H., Boccardo, P., Dequal, S., Giulio Tonolo, F., Marenchino, D., Piras, M., 2008. Low Cost UAV For PostDisaster Assessment. In: The International Archives of the Photogrammetry, Remote Sensing and Spatial Information Sciences. Vol. XXXVII. Part B8. Beijing .

Everaerts, E. 2008. Unmanned Aerial Vehicles (UAVS) for Remote Sensing and Mapping. In: The International Archives of the Photogrammetry, Remote Sensing and Spatial Information Sciences. Vol. XXXVII. Part B1. Beijing .

Grenzdörffer A , G. J., Engel B , A., B. Teichert C , B., 2008. The Photogrammetric potential of low-cost UAVs in forestry and agriculture. In: The International Archives of the Photogrammetry, Remote Sensing and Spatial Information Sciences. Vol. XXXVII. Part B1. Beijing .
Haarbrink, R. B., Koers, E., 2006. Helicopter UAV for photogrammetry and rapid response. In: ISPRS Workshop of Inter-Commission WG I/V, Autonomous Navigation.

Jesse, T., 2011, Emergency Mapping Team supplies Resources for Japan Disaster, ESRI News, Redlands, CA, USA.

John, R., 1996. Introductory Digital Image Processing-A Remote Sensing Perspective. Prentice Hall, Upper Saddle River, NJ Amsterdam, pp. 257-279.

Kim, S., Choi, J., Cho, M., Goo, S., Park, Y., 2011. Snowfall Disaster Response by Co-work with International Charter. In: 2011 Spring Conference of The Korean Society for GeoSpatial Inforamtion System, Pusan, Korea, pp. 95-100.

Lee, I., Ahn, J., Tcha, D., and Kim, S., 2011a. A Near RealTime On-Demand Retrieval of Landslide Mapping Data With Mini UVA, ISRS 2011, The Ocean Resort, Yeosu, Korea.

Lee, J., Choi, K., Lee, I., 2011b. Developments of a Real-time Aerial Monitoring System and Its Application in Emergency Mapping Teams, ISRS 2011, The Ocean Resort, Yeosu, Korea.

Lin Z., 2008. UAV for Mapping -Low Altitude Photogrammetric Survey. In: The International Archives of the Photogrammetry, Remote Sensing and Spatial Information Sciences. Vol. XXXVII. Part B1. Beijing .

Sohn, H., Cho, H., Park, H., Jung, J., Kim, S., Kim, S., 2011. A Study on fast and accurate disaster monitoring system by using LiDAR, ISRS 2011, The Ocean Resort, Yeosu, Korea.

\section{AKNOWLEDGEMENTS}

Authors would like to specially thank all volunteers for participating in EMT activities for flood and landslide disaster Last July 2011 around Seoul, Korea. 